\title{
Hércules y la fábrica de causas
}

\section{Por Massaccesi Lucas y Falco Bruno}

\section{1) Introducción}

El presente trabajo constituye una reflexión acerca del discurso consciente o inconscientemente desplegado por los operadores judiciales en el marco del tratamiento de causas penales "armadas" por las fuerzas de seguridad, pensando el papel que los medios de comunicación masiva juegan en su génesis y desarrollo. Utilizaremos el trabajo de Jerome Bruner, La Fábrica de Historias: Derecho, Literatura, Vida (2003), como eje central en torno al cual ensayar interpretaciones de la realidad judicial que día a día transitamos desde nuestro lugar dentro de una burocracia especializada en la viabilización del encarcelamiento de cientos de inocentes víctimas de las agencias penales del Estado.

Nos permitimos aclarar que con los términos "causa armada" nos estaremos refiriendo a las distintas situaciones en las que tanto fuerzas de seguridad como penitenciarias intervienen en algún momento (generalmente en los inicios) de una investigación penal o contravencional (o disciplinaria, en contextos de encierro), introduciendo en las mismas, informaciones o elementos probatorios con algún grado de falsedad, de modo tal de implicar injustamente a un/a ciudadano/a en un hecho que no cometió.

Tales prácticas suelen llevarse a cabo con distintos objetivos. En algunos casos, el armado de causa responde a fines extorsivos, amenazándose a la víctima seleccionada con que si se niega a "colaborar", es decir, si se rehúsa a pagar la coima exigida, o a aportar información para la investigación de algún hecho delictivo, o a participar en la gestión de alguna de las empresas criminales que regentean las fuerzas -tráfico de estupefacientes, robos, distribución intra o extracarcelaria de alimentos e insumos, etc.-, se la involucrará en algún hecho delictivo, ya sea a través de la falsa atribución de armas o drogas o de algún otro objeto incriminante, o a través de la introducción de algún testigo falso o anónimo que lo vincule a un delito. Otras veces, el armado responde a la necesidad de encubrir algún accionar de las fuerzas, ya sea se trate de un actuar negligente, tal como ocurrió en el conocido caso de Fernando Carrera retratado en el largometraje documental intitulado "El Rati Horror Show" -que analiza la tragedia ocurrida en el barrio porteño de Pompeya, donde policías federales sin uniforme iban persiguiendo a un auto, y confundiéndose de vehículo, abrieron fuego contra el de un inocente que, a consecuencia de los impactos de bala, atropelló y mató a peatones que caminaban por la zona-, o se trate de un accionar ilegal abiertamente doloso, tal como lo son las ejecuciones extrajudiciales que luego son presentadas ante la Justicia como el resultado de "enfrentamientos" entre el asesinado y los uniformados.

En otros casos, hechos delictivos con alguna trascendencia pública o mediática, también suelen disparar la utilización de estas dinámicas de falseamiento, porque 
ante la imposibilidad de dar con el/la autor/a real del hecho, o ante la necesidad de encubrirlo/a por ser aquél/la un/a agente de las fuerzas o tener acuerdos o vínculos familiares con algún/a agente, el involucramiento de una persona inocente deviene como una forma de "cerrar" el caso y demostrar públicamente a través de medios de comunicación, la efectividad del accionar investigativo. En el ámbito carcelario, los falseamientos de las actas donde se registran supuestas inconductas, son una práctica absolutamente cotidiana para el disciplinamiento de la población cautiva y para la gestión de los distintos circuitos de tráfico intramuros de psicofármacos o tóxicos ilegales, así como la distribución del acceso a instancias educativas, laborales, recreativas, régimen de visitas, etcétera. De la misma manera, se falsean constancias para encubrir las ejecuciones y las torturas padecidas por los/as detenidos/as: para nada excepcionales son las actas donde guardia-cárceles relatan inconductas que nunca tuvieron lugar, en aras de basamentar sanciones de aislamiento para ciertos/as detenidos/as, o describen supuestas "autolesiones" que buscan encubrir brutales golpizas.

\section{2) Operadores judiciales y multimedios}

En su texto “La Fábrica De Historias”, Bruner (2003) escribe que

los relatos seguramente no son inocentes: siempre tienen un mensaje, la mayor parte de las veces tan bien oculto que ni siquiera el narrador sabe qué interés persigue. Por ejemplo, los relatos siempre empiezan dando por descontado (e invitando al lector $\mathrm{u}$ oyente a dar por descontado) el carácter ordinario y normal de algún estado de cosas particular en el mundo (18).

En pocas dinámicas judiciales esta afirmación es tan literal como lo es dentro del inframundo penal, donde con honrosas excepciones, fiscales y jueces/zas analizan plexos probatorios construidos unilateralmente por las fuerzas del orden, sin aplicar siquiera un mínimo de suspicacia que, teniendo en cuenta las cotidianas denuncias de corrupción policial y penitenciaria, resulta indispensable para la faena.

Desde nuestro rol de operadores judiciales nos topamos día a día con víctimas del "armado" de causas, cuyas imputaciones avanzan sin contratiempos por delante de las anteojeras judiciales que acusan y condenan de manera inercial, allende de las severas inconsistencias y multivocidades que la prueba de cargo pueda contener, e incluso a pesar de las indicativas denuncias que tanto la defensa técnica como los/as propios/as imputados/as y/u organizaciones sociales interesadas, hubieren formulado sobre irregularidades policiales/fiscales en el desarrollo del proceso. Así, basta con que un policía informe falsamente haber recibido declaraciones anónimas sobre la autoría de un ilícito, para que un fiscal pida y un juez ordene la prisión preventiva de un joven, siempre y cuando el señalado pertenezca a los segmentos sociales regularmente criminalizados. Dicho encierro cautelar en conjunción con el aletargamiento de los procesos penales, y con las altas probabilidades de que en juicio resulte condenado por un aparato judicial clasista que sospecha de toda persona de tez trigueña, termina funcionando como un 
mecanismo extorsivo que impulsa al detenido, por más inocente que sea, a echar mano a cuanto recurso tenga disponible -acuerdos de juicio abreviado o suspensión de proceso a prueba- para poder poner fin a su encierro, generándosele antecedentes penales que luego serán aprovechados por las agencias del orden con fines extorsivos, y también por fiscalías y jueces que no sólo los utilizarán para fundar futuros agravamientos de condenas en eventuales causas posteriores, sino que además constituirán subrepticios e inconfesables indicios de culpabilidad para acusar y condenar al supuesto reincidente.

Dejando por fuera de nuestro análisis aquellos casos en los que las segundas intenciones del relato policial lejos de estar disimuladas, se encuentran explícitas y en sintonía con una judicatura cómplice del fraude, creemos que la dinámica de convalidación judicial sistemática de los armados policiales que señalamos, no podría ser posible sino a partir del sólido plafón creado por la omnipotente batería de asedio psicológico que constituyen los multimedios de comunicación masiva. Con sus cañones apuntados al conjunto de la sociedad en general -de donde, de más está aclararlo, surgimos quienes nutrimos la burocracia judicial-, el poder de fuego mediático focaliza en la construcción de un estereotipo de delincuente basado en la estética de los jóvenes de sectores vulnerables, no sólo moldeando ideológicamente a la audiencia sino además logrando calar en lo más hondo del subconsciente del espectador que asiste desprevenido a la yuxtaposición recurrente de sangre y altallantas. En este sentido, lo que otrora lograra la gran narrativa literaria en términos de conmoción social, tal y como relata Bruner, hoy lo consigue tanto más acabadamente la narrativa televisiva/radial/gráfica de los multimedios hegemónicos de comunicación masiva, que revolviendo los más bajos instintos del ser humano, forjan un "sentido común" cautivo, pasivamente penetrado por los dictados del aparato ideológico de los grupos dominantes propietarios de los medios de comunicación.

Cabe recordar aquí el trabajo de Alicia Ruiz, "El Derecho: entre el folletín y la tragedia" en donde se reflexiona sobre los efectos de la tensión entre ficción y realidad que plasmara Borges en uno de sus cuentos. Allí se pregunta la autora por qué lo increíble convence, respondiéndose que "Quizás algunas ficciones tienen la posibilidad de crear un 'clima' de verdad. Es más, quizás la verdad no sea sino ese 'clima' provocado por ciertas ficciones” (Ruiz, 2001). Esta dinámica climatogénica no sólo es implementada con sumo éxito en el tratamiento mediático de casos específicos (sobran ejemplos, como el "caso Ángeles Rawson” -Rodríguez, 2015-, el "caso Candela" -Kollmann, 2011-, entre tantos otros), sino que, además, día a día los medios hegemónicos de comunicación masiva trabajan minuciosamente en el mantenimiento, actualización y refuerzo de lo creado en torno a lo que se ha dado en llamar "la inseguridad", reproduciendo y multiplicando por todas las vías de comunicación disponibles cada uno de los partes policiales que relatan algún robo, homicidio o violación. Se les recuerda así a los/as pobladores/as que habrán de temer por sus vidas y sus bienes, toda vez que una horda descontrolada de pibes chorros no dudan en matar sin piedad con el fin de robar un celular o un par de zapatillas. "Con el tiempo, el compartir historias comunes crea una comunidad de interpretación, cosa de gran eficacia (...) para la cohesión cultural en general..." (Bruner, 2003:45). 


\section{3) Estereotipos catódicos como obstáculos epistemológicos}

Escribe Bruner (2003:52) que "Los seres humanos, estamos sobre todo enormemente especializados en adaptarnos al estado habitual de las cosas que nos rodean (...). No prestamos más atención y activamos el piloto automático”. Así, introyectado el modo en que generalmente han de lucir y hablar quienes delinquen [el esquema tipificador del que hablan Berger y Luckman (1986)], tan pronto la agencia policial ofrenda a la burocracia judicial un candidato que cuadre dentro del estereotipo, prácticamente ya tiene este último un pie en la mazmorra. Y más allá de que sostenemos que, a los fines de humanizar los procesos judiciales y de propender a una jurisdicción más ajustada y responsable, resulta indispensable el necesario encuentro personal del/la juez/a con el/la imputado/a, lo cierto es que las más de las veces dicha "interacción cara a cara llevará la impronta de esas tipificaciones" (Berger \& Luckman, 1986:49) previamente incorporadas por los operadores, transformándose así esas introyecciones en un obstáculo epistemológico difícilmente franqueable: "Nuestra conciencia no puede volverse ingenua por decreto, y frente a un fenómeno cualquiera no prescindimos de hecho, de nuestros conocimientos usuales" (Cárcova, 2007:8).

De esta manera, los medios de comunicación engendran y luego refuerzan diariamente el estereotipo del delincuente, dentro de un plan de operaciones más amplio dirigido a la determinación y homogenización de las prioridades políticocriminales de la población en general, y de los/as fiscales y jueces/zas en particular. Tengamos en cuenta que los operadores judiciales no sólo reciben el mensaje de los medios hegemónicos a nivel inconsciente (fundamentalmente a través de la generación y explotación del miedo) y/o ideológico (apoyando el discurso en el ensalzamiento de un perfil puramente individualista que no se cuestione en ningún momento sobre la responsabilidad de la sociedad toda por los hechos delictivos que acaecen) tal y como cualquier ciudadano de a pie, sino que además lo hacen en clave pragmática, pudiendo avizorar las altas probabilidades de que, en caso de no honrar las mandas de los multimedios hegemónicos, sus magistraturas serán pasibles de encarnizadas persecuciones y, eventualmente, de jurados de enjuiciamiento que buscarán removerlos de sus puestos de trabajo vitalicios (Ares, 2011; Quiñones, 2014). En palabras de Zaffaroni (1998:146), al/la Juez/a “...no le resta otro recurso que evitar conflictos con las otras agencias para preservar su identidad (...) y también para conservar su función: el único camino es la burocratización, o sea, las respuestas estereotipadas, la- conformidad con las pautas 'de siempre'...”. En ese marco, entonces, la narrativa policial primero, y la judicial después, se arraigan para operar "en lo que es familiar y que tiene apariencia de real” (Bruner, 2003:27), en lo que resulta previsible dentro de la compilación de realidades tesaurizadas por las líneas editoriales multimediáticas, catódicamente impuestas.

Enrique Marí (1993), al analizar el estudio foucaultiano del caso Riviere, y pensar el desajuste entre conocimiento y realidad jurídica que en dicho caso se patentizaba, afirma como tesis que entre el proceso de producción del discurso jurídico, y este mismo discurso como producto-final, se da una ostensible pero acallada ruptura lógica, que demuestra la absoluta falta de uniformidad en el 
discurso jurídico, que aunque se presente como producto de operaciones lógico formales de deducción y subsunción, en realidad conviven en su interior cientos de disputas de poder entre diferentes discursos. Es en esa puja en donde se inserta -y muchas veces prevalece- el discurso mass mediático, con los estereotipos que se dedica a instalar y a mantener vigentes.

El lenguaje que día a día vemos utilizado en los fallos, da cuenta de cuán patente es la inserción catódica en el relato judicial y con ello, teniendo en cuenta que las sentencias "Representa[n] 'la racionalidad' de una sociedad en un momento dado de su desarrollo, el conjunto de valores e ideología de una estructura político-social..." (Marí, 1993:282), podemos tomar dimensión del grado de impregnación que el estereotipo creado mass mediáticamente logra en el colectivo social.

En ese entendimiento, vemos que no son pocos los pronunciamientos donde los/as señores/as magistrados/as mechan entre sus gerundios, esdrújulas y latinazgos, alusiones al imputado bajo vocablos como "caco" o "malviviente", lo cual deja traslucir algo mucho más denso y personal que lo que debiera implicar el mero cumplimiento de la tarea propia del operador judicial. Recordaremos aquí que "Caco" era un personaje de la mitología romana vinculado con lo malvado, lo feo, lo pseudo humano, lo indeseable. Virgilio en su Eneida lo describió de la siguiente manera: "...hubo una espaciosa caverna, inaccesible a los rayos del sol, en que habitaba el horrible monstruo Caco, medio hombre y medio fiera; su suelo estaba siempre empapado de caliente sangre; en sus odiosas puertas pendían clavadas, multitud de pálidas y sangrientas cabezas" (Virgilio, 1985). Casi tres milenios más tarde, en cientos de expedientes leemos cómo ese lenguaje es ampliamente utilizado por la agencia policial, pero también por jueces y fiscales. Se llega naturalizar de tal manera, que incluso se filtra en sentencias de tribunales superiores: "si el agredido no se hubiera resistido o no hubiera agredido al caco, seguramente jamás se habría producido el disparo" -SCBA causa P. 111.207-; "no dudaron los cacos en llevar adelante la eventualidad del uso del arma de fuego" sentencia de la Sala IV del Tribunal de Casación en causa $N^{\circ}$ 61.910-; "...fue el mismo con el que los cacos interceptaron su marcha” -SCBA causa P 74.609-; "...desde el momento en que los cacos caminaron con el dinero en su poder... nada impedía que los cacos compraran algo" -Sala II de la Cámara de Apelación de Morón citada en causa SCBA P 49.266-; "no me genera duda alguna que los malvivientes al ver 'empañado' su designio furtivo, súbitamente abrieron fuego..." -misma sentencia de la Sala IV del Tribunal de Casación-). Vemos, entonces, cómo ese léxico que, utilizado hoy día, remite y responde a un derecho penal de autor que puja por retrotraer cualquier avance en torno al respeto de las garantías penales/procesales constitucionalmente consagradas, incluido entre ellas el trato digno de todo imputado como ser humano que es. Así, la ideología que informa e implementa dicho lenguaje logra imponerse en el discurso judicial, dando como resultado final una sentencia que, como productora social de significado que es, contribuye a la naturalización del estereotipo deshumanizante catódicamente generado y, en definitiva, termina decantando en una -no tan-indirecta pero segura estigmatización de la pobreza y de los ciudadanos que prestan sus cuerpos para integrar los segmentos más vulnerados de las estructuras sociales. 


\section{4) Testigos condicionados}

Pero si el discurso político-criminal de los medios hegemónicos talla en jueces y fiscales quienes, a partir de su contacto cotidiano con las realidades policiales, deberían estar dotados de una mayor capacidad de detección de lo falaz, de igual -o peor- manera influye en el resto de los/as ciudadanos/as que, eventualmente, serán quienes aporten sus testimonios en las investigaciones penales. Cobra vitalidad lo dicho por Bruner (2003:41) en punto a que "Los recuerdos basados sobre evidencias oculares o aun sobre repentinas iluminaciones están al servicio de muchos patrones, no sólo de la verdad". A este respecto, cabe destacar que unos días atrás, el periódico Página 12 publicó una entrevista a un biólogo neurocientífico del CONICET, Fabricio Ballarini, intitulando la nota con una afirmación terriblemente perturbadora lanzada por el entrevistado: "Ningún Recuerdo es Verdadero”.

Creemos que todo lo que vivimos lo podemos hacer una copia en la cabeza y que, cuando se lo evoca, se reproduce una memoria exacta. Ningún recuerdo es verdadero. Se entra en fases de olvido y cada vez que se lo evoca hay un montón de detalles que se pierden o se modifican. En un recuerdo entran en juego las emociones, los intereses, la subjetividad, si te conviene o no, a veces te conviene olvidar determinadas cosas y eso tampoco se elige. Hay estadísticas que muestran que existieron un montón de condenados a crímenes por testigos presenciales que se confundieron o le vieron la cara parecida al verdadero culpable. En situaciones de estrés, guardar una información es muy complicado y evocarlo peor. Entonces, ¿por qué habríamos de creerle a una persona que vivió esa situación? Es muy fácil implantar un recuerdo. En este experimento con los oyentes se logró implantar un recuerdo falso a un 70 por ciento desde un medio de comunicación, lo cual es inquietante (Olaberría, 2015).

Mucho más que inquietante.

A propósito de implantar recuerdos, y volviendo a la reflexión en torno a las actuaciones espurias de las fuerzas de seguridad, una práctica recurrentemente denunciada es la ilegal utilización de los álbumes fotográficos que contienen las imágenes de los delincuentes de la zona. Sobran los casos en los que puede leerse en el expediente cómo los/as testigos que pudieren brindar algún detalle en punto a la identificación del perpetrador, son llevados/as por los efectivos a la sede policial en donde, sin ningún tipo de control de la Defensa -o de cualquier otro organismo que sea ajeno a los intereses punitivistas-, les son exhibidas una serie de fotografías ${ }^{1}$ de algunos/as de los ciudadanos que alguna vez hubieren pisado un calabozo policial con motivo de alguna causa penal o por el simple hecho de haber sido víctimas de la cuestionada detención por averiguación de identidad (aclaración esta

1 También hemos tomado conocimiento de casos en donde con iguales fines, los policías acudieron a la plataforma Facebook para exhibirle a los testigos fotos de quienes quieren que resulten imputados de un hecho. 
última que en modo alguno se le realiza al testigo). Cabe destacar que las más de las veces, a los testigos no se les exhibe el álbum completo, sino que directamente se los direcciona rápidamente hacia aquellos fotografiados que a la agencia policial le interesa que sean señalados. Recordaremos aquí que el llamado reconocimiento fotográfico está previsto en varias legislaciones procesales de distintos modos; en la bonaerense, el art.261 del Código de Procedimiento estipula que "Cuando sea necesario identificar o reconocer a una persona que no está presente y que no pudiere ser habida, de la cual se tengan fotografías, se presentarán en número no inferior a cuatro (4), con otras semejantes, a quien debe efectuar el reconocimiento. En lo demás, se observarán las disposiciones precedentes [referidas a los reconocimientos en rueda de personas]. // Este procedimiento también se aplicará cuando el imputado se niegue u obstruya el desarrollo del acto". Vemos, entonces, que el Código supedita fatalmente la posibilidad de efectuar un reconocimiento fotográfico, al hecho de no poder llevarse a cabo un normal reconocimiento en rueda de personas (cnf. arts. 257 y ss. del Código procesal bonaerense). De allí que los reconocimientos fotográficos efectuados en comisarías, salvo que se hubiera imputado formalmente a una persona y se la hubiere notificado de la necesidad de que se presentare para un reconocimiento en rueda -y no hubiere concurrido-, contravienen abiertamente nuestra legislación y en modo alguno pueden ser tolerados por los operadores judiciales. No sólo eso, sino que además, incluso aceptando por hipótesis la viabilidad de los reconocimientos fotográficos dentro de nuestro ordenamiento jurídico, la imposibilidad de que la Defensa controle la producción de dicha diligencia (ya sea porque los policías los realizan a las pocas horas de acaecidos los hechos delictivos, o porque incluso cuando son realizados con posterioridad, no son notificados), hace que los recaudos previstos normativamente en salvaguarda de las garantías constitucionales, no sean cumplimentados siquiera mínimamente.

De esta manera, tenemos cientos de testigos que habiendo fijado en sus mentes uno de los rostros de las fotografías exhibidas por la agencia policial a partir de procedimientos completamente irregulares y reprochables, acuden luego a participar de reconocimientos en rueda de personas, cuyos resultados aprovechará el/la juez/a para tener por probada la autoría de un hecho delictivo investigado. Sorprende que esta práctica ostensiblemente vulneratoria de las mínimas garantías procesales, lejos de ser ocultada por las fuerzas de seguridad y los judiciales a cargo de la investigación, son recogidas y convalidadas en sentencias que niegan (explícita o implícitamente) su absoluta ilegalidad, y minimizan su incidencia determinante en los resultados de una causa penal, refiriéndolas como constitutivas de apenas meras "pautas orientativas de las pesquisas" (ver, por ejemplo, la sentencia de Sala III del Tribunal de Casación Penal de la Provincia de Buenos Aires, en la causa número 132 -No 3892 del registro de la Presidencia-, caratulada "Recurso de casación interpuesto por el Ministerio Público Fiscal en causa No 572”)².

2 Cabe aclarar que, excepcionalmente, se han dictado fallos que denunciaron la utilización de los álbumes policiales, como por ejemplo la resolución del Juzgado Contencioso Administrativo n¹ de La Plata del 8 de julio de 2005 en la causa "Asociación Civil Miguel Bru Y Otro/A C/ Ministerio De Seguridad S/ Materia A Categorizar"; o la del Juzgado de Garantías del Joven Nro. 
Sin perjuicio de lo anterior, e incluso teniendo presente que, aunque "La mente del hombre, por más ejercitada que esté su memoria o refinados sus sistemas de registro, nunca podrá recuperar por completo y de modo fiel el pasado" (Bruner, 2003:130), bajo ningún concepto pretendemos relativizar la capacidad testimonial de los individuos al punto de negar toda posibilidad de su utilización como prueba en el marco de un proceso penal. No obstante, sí resulta importante destacar que dentro de un marco normativo/jurisprudencial que impone el respeto de distintas garantías del/la ciudadano/a, entre las que se cuenta el principio de inocencia -y su derivación, "en caso de duda, se estará por la absolución"-, deviene imprescindible para los magistrados que acusan y condenan un análisis puntilloso del plexo probatorio en busca de una impoluta univocidad en punto a la identificación del imputado como perpetrador del hecho, sobre todo cuando los elementos de cargo reconocimientos en rueda $\mathrm{u}$ otras formas de testimonios. Pero incluso mediando una linealidad incontestable en la sindicación del imputado como responsable, previo a validar una versión de los hechos, es un deber impostergable del juzgador/a hacerse las preguntas indicadas por Bruner (2003:43): “¿De quién es la perspectiva [que está validando], y con qué finalidad se hipoteca, ontológica o politicamente, su relato?".

\section{5) El mito de la ecuanimidad Judicial}

Ahora bien, volviendo a la meteorología del sentido común, vemos que en el referido clima de verdad se inserta cómodamente un relato judicial que, con honrosas excepciones, termina encarcelando a quienes la hegemonía mediática señala. Y a pesar de que la inobjetable sobrerrepresentación en las cárceles bonaerenses de los jóvenes de entre 18 y 25 años provenientes de sectores populares, pone en absoluta evidencia una política-criminal arbitraria y antidemocráticamente sesgada, la confianza que la ciudadanía deposita en el sistema de justicia penal goza de salud plena, y toda propuesta mediática, política o judicial que refleje un espíritu patibulario, sigue siendo sumamente bien recibida por una buena parte de la ciudadanía.

Leemos en Bruner distintos elementos de su obra que nos ayudan a intentar explicarnos cómo es que se mantiene -más o menos- intacta dicha legitimidad de la jurisdicción:

se cimienta sobre la persuasión consolidada de que tendrán justicia en el juzgado y que serán tratados como lo fueron otros antes (...) La legitimidad del derecho reside no sólo en el solemne ritual del tribunal, sino en su arcano lenguaje especializado, que es cultivado de modo asiduo por los abogados para conservar la apariencia de la autoproclamada distancia y doctrina $(2003: 70)$.

Desde luego, Bruner reflexiona inmerso en un paradigma jurídico anglosajón que en sí mismo presupone al precedente jurisprudencial como el capítulo de la 
gran novela que todo/a juzgador/a habrá de continuar escribiendo en cada oportunidad de fallar sobre un asunto asimilable al anterior (Dworkin, 1997:165). Sin embargo, y a pesar de la distancia entre las dinámicas jurídicas continental y anglosajona, vemos que en nuestra praxis judicial la ciudadanía en general, lega en lo jurídico, se ve absolutamente cautivada y acallada por las esdrújulas y los latinazgos de los jurídicamente cultivados, y siempre y cuando vaya acorde con los lineamientos pregonados por los multimedios hegemónicos masivos de comunicación, la resolución adoptada es aceptada y validada como el resultado de un proceso ascético de desentrañamiento de la verdad histórica. Claro está que, del otro lado de las rejas, quienes soportan las persecuciones penales poco ven de objetivo e impoluto en un rito repleto de vocablos completamente ajenos a su léxico personal, oralizados por operadores con quienes no se identifican en lo más mínimo, toda vez que en nada se parecen a las personas que rodean su propia cotidianeidad, porque visten distinto, tienen otro color de piel, pronuncian de manera distinta el mismo idioma, no padecen las privaciones que él/ella y su gente padecen, etcétera. Sin embargo, la voz de estos últimos no tiene volumen político y, por ende, no sólo no permea en los ciudadanos que no son clientes del sistema penal, sino que además carece de toda posibilidad de influir en la jurisdicción.

Es en el marco de ese temor reverencial de la sociedad en general, en el que fiscales y jueces imponen categóricamente sus propios deseos -y los del segmento social de donde abrevan- de resolución de los conflictos penales, para luego buscar los rudimentos técnicos que le permitan fundar su decisión de modo que aparente ser la resolución, el resultado indefectible proceso objetivo de subsunción legal. A tal fin, sobran los recursos disponibles para alcanzar los magistrados sus objetivos: cuando la letra de la ley -en sentido formal-aplicable no coadyuve a su proyecto de resolución, siempre existe la posibilidad de echar mano a una forma de interpretación, a algún principio general del derecho, a una manda constitucional, una reglamentación, una jurisprudencia de tal o cual tribunal, un pronunciamiento de alguna Corte internacional o al criterio de algún órgano de tratado internacional: "siempre que un juez pretende haber descubierto la intención detrás de algún parágrafo de legislación, lo único que está haciendo es levantar una cortina de humo detrás de la cual el juez impone su punto de vista personal sobre lo que considera que la ley debería ser" (Dworkin, 1997:146). Además, el capital simbólico acumulado por la judicatura le permite hacer un uso -las más de las veces- impune del amplio repertorio de falacias disponibles, con una única condición de efectividad que es que la conclusión acate las líneas editoriales massmediáticas.

A este respecto, por demás interesante resulta la reflexión de Duncan Kennedy (1999:91) en torno al proceso de construcción de una decisión jurisdiccional. Dice el autor que siempre se presenta el “conflicto entre lo que 'la ley' exige y 'lasentencia-a-la-que-yo [juzgador]-quiero-llegar”,", proceso que termina siendo dirimido por alguna/s de las múltiples eventuales motivaciones que puedan estar en juego: expectativas en torno a la recepción del fallo en la comunidad (jurídica o civil), reproducción de los criterios del órgano que eventualmente revisará el pronunciamiento, formación política y/o ideológica del juez/a, sobornos, intento de ganar un favor político, etc. Baste referirnos, para ejemplificar lo señalado, lo 
que ocurre en la dinámica de las excarcelaciones en el proceso penal -bonaerense, al menos-, donde incluso a pesar de ostentar nuestro ordenamiento jurídico normas como el propio art.18 de la Constitución Nacional que establece que "ningún habitante de la Nación puede ser penado sin juicio previo...", y con el art.21 de la Constitución Provincial que establece como regla que "podrá ser excarcelada o eximida de prisión la persona que diere caución o fianza suficiente...", siempre que el/la imputado/a encaje en el estereotipo criminal massmediáticamente impuesto, la judicatura habrá de acudir invariablemente a la prisionización preventiva del acusado, subvirtiendo así las mandas constitucionales que estipulan la libertad durante el proceso como regla. A tal fin, bastará con afirmaciones dogmáticas que declamen la supuesta existencia de "peligros procesales", para encarcelar a una persona sin condena. En última instancia, "la argumentación jurídica no es otra cosa que la manipulación del material jurídico" (Kennedy, 1999:122).

No obstante lo anterior, la plasticidad del ordenamiento jurídico pasa a un plano secundario cuando de desarmar causas se trata. En estos casos, la relevancia máxima radica en el grado de perspicacia que se utilice a la hora de revisar críticamente el plexo probatorio llevado a juicio. La tesitura que adopte la judicatura (y el/la mismo/a fiscal que, conforme la normativa procesal bonaerense, tiene que "adecuar sus actos a un criterio objetivo debiendo formular los requerimientos e instancias conforme a este criterio, aún a favor del imputado" art.56 CPP-) a la hora de evaluar los elementos de cargo y descargo que hubieren sido recabados o referidos, terminará decidiendo la opción por una respuesta conforme hegemonía o, por el contrario, por una contrahegemónica.

De decidirse por la primera de las opciones, esto es, condenar a la víctima que las fuerzas de seguridad seleccionaron para sufrir injustamente la prisión, teniendo presente lo dicho en cuanto a la función del discurso jurídico como creador de sentido, el magistrado termina legitimando y reforzando el estereotipo massmediáticamente impuesto del delincuente. En ese caso, el/la juzgador/a podrá estar tranquilo de que los sectores de la sociedad cuyas voces tienen verdadero peso institucional (y que, eventualmente, podrían generarle inconvenientes a su estabilidad laboral) secundarán su decisión en tanto coincida con la realidad catódicamente impuesta, es decir, siempre que el condenado sea un joven de tez morena, ropa deportiva y gorra, y con un léxico atravesado por el argot carcelario. Claramente será ésta la decisión que menos consecuencias negativas le acarree al magistrado (si sacamos de la base de cálculo a la moral, claro está), suponiendo el reducido costo de verse obligado a fingir -en mayor o menor medida, dependiendo de su propia capacidad crítica- que lo/a embarga la firme convicción de la culpabilidad del/a imputado/a, incluso a pesar de los distintos puntos oscuros que pudiere haber notado en el plexo probatorio como ser, por ejemplo, que la prueba se reduzca a meras declaraciones policiales, o que las llamadas anónimas sean de dudosa procedencia, o que diversas líneas hipotéticas exculpatorias no hubieren sido debidamente investigadas, o que los/as testigos hubieren sido inexactos/as o condicionados previamente, etc.); en última instancia, cuando el/la imputado responda a la estética de lo feo (Zaffaroni, 1998:134-135), de lo marginal, de lo que probablemente haya delinquido o, en todo caso, vaya a delinquir en el corto plazo, 
su condena aunque no se apoye en la verdad de lo sucedido, tampoco será una carga tan pesada a la hora de conciliar el sueño.

Por el contrario, la opción por la alternativa contrahegemónica, como tal, supone necesariamente consecuencias ["Mi poder legitimador se reduce o aumenta sólo cuando intento hacer algo fuera de lo común" (Kennedy, 1999:127)]. Hemos de decir que, excepcionalmente las mismas pueden tener matices positivos, toda vez que una resolución de este tipo puede redundar en un mejor posicionamiento relativo del/a juzgador/a para con un determinado grupo progresista, por ejemplo; pero sin lugar a dudas, la reiteración de elecciones contrahegemónicas habrá tarde o temprano de acarrear represalias de los factores de poder real, máxime cuando la hegemonía que se ataca no sólo cuenta con la opinión pública massmediáticamente manipulada en su favor, sino que además el orden de cosas por ésta establecida protege y ampara el funcionamiento de organizaciones criminales estatalmente amparadas, cuyo accionar delictivo quedaría irremediablemente expuesto por una decisión judicial que denuncie las manipulaciones en las investigaciones.

\section{Palabras finales}

El discurso jurídico se construye en un entretejido de discursos sociales diversos, aludidos y eludidos en cada tramo de esa construcción - y no por azar-. No deviene ni de la pura razón, ni de dios; es parte de la cultura, es contingente y cambiante, es opaco, atravesado por ficciones, y su trama es la de un relato peculiar que constituye realidades, relaciones, sujetos, que legitima o deslegitima pedazos del mundo (...) (Ruiz, 2014)

Los/as jueces/zas y fiscales son los/as principales protagonistas y factores/as de dicho discurso jurídico, y es precisamente de ellos/as de quienes pende el encarcelamiento de ciudadanos/as inocentes injustamente acusados de haber cometido hechos fraguados por las fuerzas de seguridad. La perspicacia, decencia y valentía de cada magistrado/a es puesta a prueba una y otra vez por las lógicas mafiosas del crimen organizado al servicio de los poderosos, en un marco dentro del cual los sectores populares no sólo sufren la marginalidad impuesta por el modelo económico y la estigmatización por estereotipación, sino que además padecen la crueldad de un poder punitivo que pesa billeteras para decidir la reclusión en las condiciones carcelarias más violentas e inhumanas que puedan imaginarse.

Resulta fatalmente decisiva la comprobada capacidad de los medios de comunicación a la hora de construir hegemonía en torno a las facetas de la vida democrática, pero especialmente visible es la influencia que ejercen en materia

político-criminal. Asimismo, imponen nuevas lógicas comunicacionales ("Planos breves, repetición y acumulación de imágenes" -Ruiz, 2001-) que tornan verdaderamente dificultosa la resistencia de los bienintencionados, sobre todo en un paisaje de concentración de la propiedad de los medios de comunica(manipula)ción masiva, no sólo en escala nacional sino además regional e incluso global. 
Con el pesimismo de la inteligencia, nos permitimos decir que los Hércules (conforme Ost, 2007) del mundo jurídico penal poco pueden hacer para sobreponerse a una Hidra massmediática que cumple su misión de manera sumamente eficaz. Con el optimismo de la voluntad, creemos que, en la praxis cotidiana, cada inocente que es librado del encarcelamiento injusto, significa una verdadera contribución insoslayable a la que está obligado/a todo/a operador/a jurídico en el marco de la responsabilidad transgeneracional que nos impone la función pública. A diferencia de lo sucedido en el relato mitológico, los/as Hércules de nuestros días debemos sacar a relucir nuestra suspicacia y no dejarnos engañar por lo que se nos presenta como ostensible: el hecho de que mujan los bueyes en la caverna de Caco, no significa que Caco haya perpetrado del hurto. 


\section{Bibliografía}

Ares, J. L. (2011). Caso Sal Lari: absurdo y paradójico. Recuperado de http://www.pagina12.com.ar/diario/sociedad/3-166942-2011-04-25.html.

BRUNER, J. (2003). La fábrica de historias. Derecho, literatura, vida. Méjico DF: Fondo de Cultura Económica.

BERGER, P. L. Y LUCKMANN, T. (1986). La construcción social de la realidad. Buenos Aires: Amorrortu.

CÁRCOVA, C. M. (2007). Las teorias juridicas post positivas. Ciudad Autónoma de Buenos Aires: Lexis Nexis.

DWORKIN, R. (1997). Cómo el derecho se parece a la literatura. En La decisión Judicial. El debate Hart-Dworkin, estudio preliminar de César Rodríguez. Bogotá: Universidad de los Andes, Siglo del Hombre editores.

KENNEDY, D. (1999). Libertad y restricción en la decisión judicial: una fenomenología crítica. Bogotá: Siglo del Hombre Editores.

KOLlMANN, R. (2011). El complicado caso Candela. Recuperado de http://www.pagina12.com.ar/diario/sociedad/3-179531-2011-10-23.html.

MARÍ, E. E. (1993). Papeles de Filosofía. Buenos Aires: Editorial Biblos.

OLABERRÍA, G. (2015). 'Ningún recuerdo es verdadero'. Recuperado de http://www. pagina12.com.ar/diario/dialogos/21-287216-2015-11-30.html

OST, F. (2007). Júpiter, Hércules y Hermes: tres modelos de juez. Academia. Revista sobre enseñanza del Derecho, Año 4, Número 8.

QUIÑNONE, R. (2014). Mirando la paja en el ojo ajeno. Recuperado de http://www.pagina12.com.ar/diario/sociedad/3-248176-2014-06-09.html

RUIZ, A. E. C. (2001). Idas y vueltas. Por una teoría crítica del derecho. Ciudad Autónoma de Buenos Aires: Facultad de Derecho, Universidad de Buenos Aires.

RUIZ, A. E. C. (2014). Jueces y memoria. Jurisprudencia Argentina "Los derechos fundamentales en la constitución: interpretación y lenguaje", Número especial, Fascículo 9.

RUIZ, A. E. C., DOUGLAS PRICE J. E. \& CÁRCOVA C. M. (2014). La letra y la ley: estudios sobre derecho y literatura. Ciudad Autónoma de Buenos Aires: Infojus.

RODRÍGUEZ, C. (2015). Mangeri, perpetua por el femicidio de Angeles. Recuperado de http://www.pagina12.com.ar/diario/sociedad/3-277217-2015-0716.html

VIRGILIO. (1985). La Eneida. Madrid: Editorial Edaf.

ZAFFARONI, E. R. (1998). En busca de las penas perdidas. Ciudad Autónoma de Buenos Aires: Sociedad Anónima Editora Comercial Industrial y Financiera. 
